\title{
Action Research: An Ethno-methodological Perspective
}

\author{
Vinija N. S. \\ Research Scholar \\ Bharathiyar University \\ Coimbatore, Tamil Nadu, India \\ vinija78@gmail.com \\ Dr. P Bhaskaran Nair \\ Professor of English \\ Hindustan University \\ Chennai, Tamil Nadu, India
}

\begin{abstract}
Action Research is a tool for professional development which gained considerable momentum in language teaching domain. Effective and meaningful professional development programmes involve teachers in the constant process of learning about their practices, discovering and using their own potential. The strategies employed in action research are found to be one of the best options that can engage teachers in meaningful self-improvement. It is a discovery process in which the teacher investigates the issue on focus, carries out and implements some actions in the classroom. Just in opposite direction of the traditional practice of 'from theory to practice', action research moves 'from practice to theorizing'. Reflection which is the essence of the philosophy at work behind, action research has a crucial role in improving the learning process
\end{abstract}


and enhancing professional development. Reflection involves cognition, critical thinking, evaluation and problem solving. Action research continuously prompts these processes.

This article attempts to project how action research functions as a two-pronged phenomenon: (i) a pedagogic tool, whose impact will explicitly be felt on the learner, and (ii) as a means of continuous professional development, which leaves an implicit but, long-lasting change in the teacher. It is also pointed out in the paper, how action research can alter the physical and mental environment of learning and teaching through an ethno-methodological functioning - the teacher and the learners living in the same environment and getting immersed in the same experience.

Introduction

Teacher professional development is crucial for teachers to function successfully. Reflective teaching is the master key to accelerate effective professional development and elevate the skill of teachers. The use of reflective practice in teachers' professional development is based on the belief that teachers can improve their own teaching by consciously and systematically reflecting on their teaching experiences (Farrell, 2004, 2007). Reflection, which is the essence of action research philosophy, has a crucial role in improving the learning process and enhancing professional development. Teachers have to reflect systematically and consistently on their instructional practices. This paper investigates how action research strategies are found to be one of the best options that can engage teachers in meaningful self-improvement through an 'ethno-methodological' functioning. 
Ethno methodology \& Action research - Definition \& Functioning

Basically, "Ethno methodology is an approach within sociology that focuses on the way people, as rational actors; make sense of their everyday world by employing practical reasoning rather than formal logic. It concentrates on how people make sense of the everyday aspects of their world and how they make their social environment accountable to themselves."

Action research is a form of self-reflective enquiry undertaken by participants in social situations in order to improve the rationality and justice of their own practices, their understanding of these practices, and the situations in which the practices are carried out. (Carr and Kemmis, 1986).

Action research follows an 'ethnographic approach'. While doing action research, the teacher and the learners living in the same environment and getting immersed in the same experience. The teacher gets very much involved in the whole research and identified himself/herself with its participants. Being with a teaching learning community, the teacher is experiencing the practical problems, trying to problematize the kernel issues, locating those issues within the available theoretical framework and progressing through the deviant roots which appear ahead, sharing the rewards and hard spots in teaching learning and thus finally arrive at a different way of dealing with difficult issues and situations. This growth can be attributed mainly to the fact that the inquiry comes from real-world observations and dilemmas. Action research encourages teachers to (1) engage in the study of their own practice; (2) develop their own educational theories deriving from that practice (McNiff with Whitehead, 2006).

Ethno methodology is not a third person reporting, but a first person narrating, occasionally a soliloquy, quite often an aside (speaking aloud to oneself). This dramatic device of soliloquizing or speaking aside is a mode of self-reflection. Therefore, ethno methodology and 
experiential experiments are a form of reflection. Experiential research serves as the foundation of action research. Action research when carried out in an ethno methodological framework converges the objectives of both the teacher and the researcher (in him/her). The traditional progress from theory/ research to classroom application finds a reverse course in Action research. Just in opposite direction of the practice of 'from theory to practice', action research moves 'from practice to theorizing'. It is process oriented. The research product and the research process get merged at a point in progress. The object of inquiry for both the teacher and the researcher is one and the same. Therefore, there is no question of alienation.

Reciprocity is inherent at two levels in an action research- mutual give and take between the learner and the teacher. And there is a mutual complementing between the teacher and the researcher in one person. For example, lack of communicative competence is an issue not only to the learner, but to the teacher as well. Lack of communicative competence being an issue, it needs to be addressed at both sides. To solve this issue, at first, the teacher reflects on his/her actions/strategies, then plans, acts, observes and reflects again. The teacher cannot blindly copy any theory or strategy as it may not suit well to his/her classroom. Therefore, the teacher himself/herself seeks and find out the solution to overcome the issue. That is to say, guiding the insufficiently competent learner to optimal competence level is likely to end up as a means of developing teacher's whole competence.

\section{Conclusion}

Action Research unlike formal educational research need not follow a monolithic theoretical framework. On the other hand, any one facet of that huge portion will suffice to ground an action research. The co-existence of a teacher and a researcher in the same person 
adds advantage to both research and teaching. But at the same time, there are chances of disadvantages too - teaching can be over-shadowed by research. Moreover, the intensity of research may go compromised as it is likely to be surrendering itself to pedagogy. Yet there is an advantage of establishing part-whole relationship between Action Research and formal educational research.

Action research provides a new horizon for teachers to explore their instructional practices and become better professionals. It enriches their practical and professional knowledge to a great extent. It serves the purpose of bridging the gap between theory and practice. Through action research, teachers are not just consumers of others' theories, but they are reflective practitioners who can confidently decide for their own theories to enhance their professional status. 


\section{References}

Carr. W. \&Kemmis, S. (1986). Becoming critical: Education, knowledge and action research. New York: Routledge. (https://www.jstor.org/stable/23768771)

Richards, Jack C. (2010). Professional Development for Language Teachers. NewDelhi: Cambridge

McIntosh, Paul. (2010) Action Research and Reflective Practice. New York: Routledge.

Harvey, L., 2012-20, Social Research Glossary, Quality Research International, http://www.qualityresearchinternational.com/socialresearch/

P, Ramalingam. (2008) Action research as an interface between teacher education and applied research In Applying Psychology in Teacher Education. Puducherry Co-op. Book Society

Anastasia, Stavridou. (2017) Ethnography as an Approach to Language-and-culture Teaching and Learning. THEWARWICKELTEZINE

https://www.beta-iatefl.org/834/blog-publications/ethnography -languageeducation/ 